\title{
Divorce Related Malicious Mother Syndrome
}

\author{
Ira Daniel Turkat
}

from Journal of Family Violence, Vol. 10, No. 3. 1995 p 253-264

With the increasing commonality of divorce involving children, a pattern of abnormal behaviour has emerged that has received little attention. The present paper defines the Divorce Related Malicious Mother Syndrome. Specific nosologic criteria are provided with abundant clinical examples. Given the lack of scientific data available on the disorder, issues of classification, etiology, treatment, and prevention appear ripe for investigation.

\section{INTRODUCTION}

A divorced man gains custody of his children and his ex-wife burns down his home. A woman in a custody battle buys a cat for her offspring because her divorcing husband is highly allergic to cats. A mother forces her children to sleep in a car to "prove" their father has bankrupted them. These actions illustrate a pattern of abnormal behavior that has emerged as the divorce rate involving children has grown.

Today, half of all marriages will end in divorce (Beal and Hochman, 1991). The number of children involved in divorce has grown dramatically (e.g., Hetherington and Arastah, 1988) as well. While the majority of such cases are "settled" from a legal perspective, outside the courtroom the battle continues.

The media has spent considerable effort raising public awareness about the problem posed by divorced fathers who do not provide court ordered child support payments. Hedges (1991) has noted that less than $20 \%$ of divorced fathers provide child support payments three years after their divorce. Research on the decline of women's economic status following divorce (e.g., Hernandez, 1988; Laosa, 1988) has contributed to recent legislation to address the "Deadbeat Dad" problem.

While the media correctly portrays the difficulties imposed upon women and children by the "Deadbeat Dad" phenomenon, the cameras have yet to capture the warfare waged by a select group of mothers against child support paying, law abiding fathers. Every day, attorneys and therapists are exposed to horror stories in which vicious behaviors are lodged against innocent fathers and children. Unfortunately, there are no scientific data on the subject. Similarly, the clinical literature has relatively ignored the problem.

A notable exception can be found in the clinical writings of Gardner $(1987,1989)$ who has provided excellent descriptions of the Parental Alienation Syndrome. Here, a custodial parent

Ira Daniel Turkat can be reached at the

Florida Institute of Psychology and University of Florida College of Medicine, 1225

Avenida Del Circo, Venice, Florida 34285. 
successfully engages in a variety of maneuvers to alienate the child from the non-residential parent. Once successfully manipulated, the child becomes "...preoccupied with deprecation and criticism of a parent-denigration that is unjustified and/or exaggerated" (Gardner, 1989 p. 226). In the typical case of Parental Alienation Syndrome, both mother and child engage in an array of abnormal actions against the rather. Gardner views "brainwashing" as a concept "too narrow" (Gardner, 1989) to capture the psychological manipulation involved in turning a child against his/her non-residential parent.

While Gardner's pioneering descriptions of the Parental Alienation Syndrome provide an important contribution to our understanding of divorce related child involved hostilities, the present paper is concerned with a more global abnormality. As noted in the examples provided in the beginning of this manuscript, serious attacks on divorcing husbands take place which are beyond merely manipulating the children. Further, these actions include a willingness by some mothers to violate societal law. Finally, there are mothers who persistently engage in malicious behaviors designed to alienate their offspring from the father, despite being unable to successfully cause alienation. In sum, these cases do not meet the criteria for Parental Alienation Syndrome. Nevertheless, they portray a serious abnormality.

The purpose of the present paper is to define and illustrate this more global abnormality with the hope of generating increased scientific and clinical investigation of this problem.

\section{DEFINITION}

The present section provides a beginning definition of the Divorce Related Malicious Mother Syndrome, which has been derived from clinical and legal cases. As in all initial proposals, it is anticipated that future research will lead to greater refinement in the taxonomic criteria. The proposed definition encompasses four major criteria, as follows:

1. A mother who unjustifiably punishes her divorcing or divorced husband by:

a. Attempting to alienate their mutual child(ren) from the father

b. Involving others in malicious actions against the father

c. Engaging in excessive litigation

2. The mother specifically attempts to deny her child(ren):

a. Regular uninterrupted visitation with the father

b. Uninhibited telephone access to the father

c. Paternal participation in the child(ren)'s school life and extra-curricular activities 
3. Tile pattern is pervasive and includes malicious acts towards the husband including:
a. Lying to the children
b. Lying to others
c. Violations of law

4. The disorder is not specifically due to another mental disorder although a separate mental disorder may co-exist.

\section{CLINICAL ILLUSTRATIONS}

In this section, I will provide clinical illustrations for each criterion using the reference numbers provided above. As criteria 1-3 are behavior specific to the Malicious Mother Syndrome, I will provide a series of clinical examples. The fourth criterion which addresses the relationship of the proposed syndrome to other mental disorders, will be discussed more generally.

\section{Criterion 1A: Alienating the Children}

The range of actions taken by a mother to attempt to alienate her children from their father is impressive. For example:

One mother lied to her children that she could no longer buy food because their father had spent all of their money on women at topless bars.

A doctor's wife forced her 10 year old son to apply for federally funded free school lunches to delude the boy that his "daddy has made us poor."

A woman who for years was very close to the children in a custody battle, was asked by their mother to give up neutrality and join her campaign against the father to "dance on his grave." When the friend refused to give up her neutrality, the mother falsely informed her children that their father was having an affair with this woman.

These behaviors, if successful, could lead a child to not only hate the father but perhaps go years without seeing him. As Cartwright (1993) has noted: "The goal of the alienator is crystalline: to deprive the lost parent, not only of the child's time, but of the time of childhood" (p. 210).

\section{Criterion 1B: Involving Others in Malicious Actions}

The second component of the first major criterion where the mother attempts to punish the husband, involves manipulating other individuals to engage in malicious acts against the father. Examples of this kind are as follows:

During a custody battle, a mother lied to a therapist about the father's behaviour. The therapist, having never spoken with the father, appeared as an "expert" witness to inform the 
judge that the mother should be the primary residential parent and that the father needed to be in therapy.

One angry mother manipulated teenagers to leave anonymous threatening notes at the ex-husband's home.

A mother who had lost legal custody of her child, manipulated a secretary at the child's school to assist in kidnapping the child.

In the above examples, it is important to note that the person manipulated by the angry mother has, in a way, been "alienated" against the divorcing husband. Typically, the individual "duped" takes on a righteous indignation, contributing to a rewarding climate for the mother initiating malicious actions.

\section{Criterion 1C: Excessive Litigation}

There is little question that either party in a divorce or custody proceeding is entitled to appropriate legal representation and action. Individuals suffering from Divorce Related Malicious Mother Syndrome, however, attempt to punish the divorcing husband by engaging in excessive litigation.

A belligerent and unreasonable mother verbally attacked her ex-husband whenever she saw him. Over time, his response was to ignore her. She then took him to court, asking the judge to require the ex-husband to talk with her.

One mother told a judge that her daughter was not really her divorcing husband's child.

One woman refused to stop attacking her ex-husband through the courts despite numerous attorneys being fired or voluntarily leaving the case. Over a three year period, seven different attorneys were utilized.

Data exist which can help in determining the range of excessive litigation. For example, Keel et al. (1988) report on the frequency of post-divorce litigation in a sample of 700 families. Their data indicate that only $12.7 \%$ of families file one post-divorce petition to the court, whereas less than $5 \%$ file two or more petitions (Keel at al. 1988); less than $1 \%$ file four or more petitions.

\section{Criterion 2A: Denying Regular Visitation}

Experts are in relative agreement that regular and uninterrupted visitation with the non-residential parent is desirable and beneficial for children, except in extreme circumstances (Hedges, 1991). In fact, some states, such as Florida, have laws written to reflect this view (Keane, 1990). Unfortunately, even when the father and children have legal rights to visitation, individuals with Divorce Related Malicious Mother Syndrome continue to interfere with it.

A mother who previously attacked her ex-husband physically during visitation transfers of the children, refused to provide the children when the ex-husband had the police attend to monitor exchanges. 
When one divorced father arrived to pick up his children for visitation, the mother arranged for her and the children to be elsewhere so that the father could not visit with the children.

One mother had her physically intimidating boyfriend assault her ex-husband when he came to pick up his children for visitation.

The President of The Council for Children's Rights (Washington, D.C.) notes that such alienation is considered a form of child abuse (Levy, 1992). Unfortunately, the police typically avoid involving themselves in such situations. Furthermore, unless a victimized father is financially capable of returning to court on an ongoing basis, there is little that can be done to prevent such mothers' behavior. Finally, even when such cases are brought to trial, the courts are often inadequate in supporting fathers' visitation rights (Commission on Gender Bias in the Judicial System, 1992).

\section{Criterion 2B: Denying Uninhibited Telephone Access}

Given the physical absence of one parent, the telephone plays an important role in maintaining the bond between child and non-residential parent. Individuals suffering from Divorce Related Malicious Mother Syndrome engage in an array of actions designed to circumvent telephone access.

A father called to speak to his children and was told that they were not at home when in bet he could hear their voices in the background.

When one father called to speak with his children, the mother put him on "hold," informed no one, and then left him there.

Knowing that the children's father was away on vacation, one mother encouraged them to leave several messages on his answering machine to call back immediately only if he would like some additional visitation time with his children.

Some fathers find the alienation attempts so painful and fruitless that they eventually are extinguished from calling their children; they simply "give up." Placed in a no-win scenario, the father's "abandonment" (Hedges, 1991) unfortunately achieves the precise result aimed for by the individual suffering from Divorce Related Malicious Mother Syndrome.

\section{Criterion 2C: Denying Participation in Extra-Curricular Activities}

An integral part of the process of maintaining one's bond with one's child is to participate in activities that one did before the parents separated. School plays, team sports, and religious events are just some of the types of activities of importance. Malicious Mothers frequently engage in maneuvers designed to prevent participation in these activities.

One father was deliberately given the wrong date and time for an important event for the child. The child was asked by the mother, "I wonder why your father didn't want to come to see you today"? 
One mother refused to provide the father with any information about any extra-curricular activities in which the children were engaged.

Prior to a child's soccer game, one mother told many of the team parents disparaging falsehoods about the visiting lather. When he came to watch his son's soccer game, many of these parents looked at him with angry eyes, refused to talk with him, and walked away when he moved toward them.

Malicious Mothers who engage in such behaviors rarely have to face penalties for such actions. Judges, attorneys, and policemen cannot involve themselves in every instance of blocked paternal access. Furthermore, most fathers cannot afford the financial requirements involved. As such, the cycle of access interference perpetuates itself.

\section{Criterion 3A: Malicious Lying to the Children}

Given their developmental status, children in a disputed divorce situation are quite vulnerable. When one parent decides to attack the other by lying to the children, examples of this type of malicious behavior may include some of the following.

One divorcing mother told her very young daughter that her father was "not really" her father even though he was.

An eight year old girl was forced by her mother to hand unpaid bills to her lather when he visited because the mother had falsely told the daughter that the father had not provided any economic means of support to the family.

One mother falsely told her children that their father had repeatedly beat her up in the past.

These examples of malicious lying can be contrasted with the more subtle maneuvers typically seen in Parental Alienation Syndrome, such as "virtual allegations" (Cartwright, 1993). Here, the mother setting up a Parental Alienation Syndrome may hint that abuse may have occurred, whereas the individual suffering from Divorce Related Malicious Mother Syndrome falsely claims that abuse has actually occurred.

\section{Criterion 3B: Malicious Lying to Others}

Individuals suffering from Divorce Related Malicious Mother Syndrome may engage a wide range of other individuals in their attacks upon the ex-husband. However, with this particular criterion, the individual with Divorce Related Malicious Mother Syndrome specifically lies to other individuals in the belligerency against the father. Some examples include the following.

One furious mother called the president of the (1500 employee) workplace of her divorcing husband, claiming falsely that he was using business property for personal gain and was abusing their mutual children at his work locale.

One woman falsely told slate officials that her ex-husband was sexually abusing their daughter. The child was immediately taken away from him and his access to her was denied. 
During the course of a custody dispute, one mother falsely informed the guardian, who was investigating the parenting skills of each parent, that the father had physically abused her.

Snyder (1986) has reported on the difficulty imposed upon legal authorities when confronted with someone who is an excellent liar. Consistent with research on the inability of "specialists" to detect lying (Ekman and O'Sullivan, 1991), a skilled fabricator can be a compelling witness in the courtroom (Snyder, 1986). While sometimes seen in borderline personalities, Snyder (1986) notes that pathological lying (Pseudologia Fantastica) is not restricted to that particular character disorder.

\section{Criterion 3C: Violating Law to Attack the Husband}

Individuals suffering from Divorce Related Malicious Mother Syndrome have few if any boundaries in their campaign against the divorcing husband. Violations of law are common in many cases, although the laws broken may be relatively minor. However, in some cases, the violations of law may be quite serious.

One woman deliberately drove her automobile into the house of her ex-husband where their mutual children resided.

In the midst of a custody battle, one woman broke into the residence of her divorcing husband and stole important business papers.

An angry divorcing mother called a Christian evangelical television station and pledged $\$ 1000$, giving the name, address, and phone number of her divorcing Jewish husband as the pledgee.

The above descriptions may remind the reader of certain personality disorders (e.g., antisocial, borderline, sadistic) but these behaviors may be demonstrated by individuals with Divorce Related Malicious Mother Syndrome who do not appear to meet official diagnostic criteria for an Axis II disorder. Further, in each of the four examples provided above, none of the Malicious Mothers involved was sentenced for such behavior by a Judge.

\section{Criterion 4: Not Due to Another Disorder}

In assessing the Divorce Related Malicious Mother Syndrome, it is important to note that many of the above clinical examples seem to have occurred in individuals who had no prior mental disorder diagnosis or treatment. In fact, one mother who engaged in extreme maliciousness toward her divorcing husband had several mental health professionals testify that she was not suffering from any type of mental disorder. Clearly, it would seem that individuals who have Divorce Related Malicious Mother Syndrome may or may not have a concomitant mental disorder.

In the author's experience, for each mental disorder that might come to mind to account for some of this behavior, an exceptional case presents. For example, in some cases an Adjustment Disorder might seem an appropriate diagnosis, yet one woman still denied her ex-husband visitation 10 years after the divorce. Other cases might suggest a possibility of a personality 
disorder diagnosis, yet one woman who repeatedly violated the law in attacking her ex-husband, received no personality disorder diagnosis despite being evaluated by masters level and doctoral level examiners. In some instances, Intermittent Explosive Disorder might be considered, yet the anger for many of the mothers does not appear to be intermittent.

Finally, the reader should appreciate that while diagnostic accuracy for certain psychiatric difficulties is not as good as one would like (e.g., the personality disorders, see Turkat, 1990), the problem is compounded in family law where incompetent mental health examiners sometimes become involved in the judicial process (Turkat, 195)3). Clearly, the relationship between Divorce Related Malicious Mother Syndrome and other mental disorders is a complex one which requires significant investigation.

\section{DISCUSSION}

The above description of the Divorce Related Malicious Mother Syndrome raises a variety of important clinical, legal, and scientific issues.

From a clinical perspective, families that involve a Divorce Related Malicious Mother Syndrome are subject to serious episodes of stress and distress. Yet, there is no scientific evidence on how to treat this phenomenon. It is particularly compromised by the fact that many of these cases that appear to meet the proposed diagnostic criteria deny that there is anything wrong with them.

An additional difficulty is that many therapists are unaware of this pattern of malicious behavior (Heinz and Heinz, 1993). As such, there are therapists who are "fooled" by such cases and, as noted earlier, will come to court testifying that there is nothing wrong with the mother involved.

From a legal perspective, there are some attorneys who may unintentionally encourage this type of behavior (Gardner, 1989). On the other hand, there are some attorneys who deliberately encourage such behavior, as the financial rewards for them are time dependent. In other words, the more involved the litigation process, the greater the profits for the attorney (Grotman and Thomas, 1990). However, even for the subset of attorneys for whom this may be true, there is a point of diminishing returns. Furthermore, independent of economic considerations, many who become involved with family law courtrooms find that these types of cases are not handled well (Greif, 1985; Levy, 1992).

The woman who is not disturbed "enough" to lose custody of her children in the courtroom will not have money denied to her because she engages in this behavior; nor will she go to jail. Thus, many clients report significant frustration when they and their children are exposed to this type of behavior, and the courts seem to do little if anything about.

In a review of pertinent law literature on bias against men in family law proceedings, Tillitski (1992) concluded that there is widespread discrimination. This is well illustrated by one family law Judge's statement that, "I ain't never seen the calves follow the bulls, they always follow the cow; therefore, I always give custody to the mamas" (Commission on Gender Bias in the Judicial System, 1992 p. 742). Similarly, it is noted that visitation rights of fathers are not enforced as rigidly as are child support orders (Commission on Gender Bias in the Judicial 
System, 1992). Such bias against men in family law proceedings results in a unique group of fathers who unintentionally become relatively helpless victims of the system (Tillitski, 1992). This situation would seem to reinforce much of the vicious behavior displayed by women suffering from Divorce Related Malicious Mother Syndrome.

The issue of sex distribution of the disorder certainly needs to be addressed. The overwhelming majority of custodial parents are female (Commission on Gender Bias in the Judicial System, 1992). Gardner (1989) has noted that Parental Alienation Syndrome appears most commonly in females, although it is possible for a male who has custody of the children to engage in the same type of alienating behaviors. The author's experience with Divorce Related Malicious Mother Syndrome is similar to Gardner's. However, the present writer has yet to see a case of a father engaging in all of the criteria listed. This does not mean that it is not possible for there to be a "Malicious Father" Syndrome. In fact, Shepard (1992) reports that there is significant abuse of some custodial mothers by non-residential fathers. On the other hand, it should be noted that there are females who are required to pay chiltl support, but we have yet to heara about "Deadbeat Moms." Given at the present time that a case in which the father met all of the criteria for Divorce Related Malicious Mother Syntlrome has yet to be documented, it appears advisable to await scientific evidence to guide issues of nosologic labeling.

How prevalent is the Divorce Related Malicious Mother Syndrome? The answer is unknown. Gardner (1989) reports that approximately $90 \%$ of all custody battles involve some aspects of parental alienation. Further, Kressel (1985) reviewed data indicating that up to $40 \%$ of maternal custodians denied visitation to the ex-husband in order to punish him. Relatedly, Arditti (1992) reported that $50 \%$ of a sample of divorced fathers $(\mathrm{N}=125)$ indicated that visitation was interfered with by the mother. While aspects of parental alienation may be common, it is highly unlikely that such a percentage of maternal custodians would meet all of the criteria for Divorce Related Malicious Mother Syndrome.

In regard to incidence, it would appear through the title of this syndrome that the malicious behavior is precipitated by the divorce process.

However, this is clearly an empirical question. While the malicious actions may first be noted during a divorce process, it is possible that maliciousness may have been present earlier but undetected. Research on pre-divorce parental conflict (Enos and Handal, 1986) supports this speculation. Relatedly, it may also be that there are some cases of pre-existing mental disorder that have not been discovered until the stress of the divorce itself unfolds.

Finally, it should be noted that research on the nature of post-divorce family functioning is beginning to emerge. Some data exist on the role of parental conflict in children's postdivorce functioning (e.g., Frost and Pakiz, 1990; Furstenberg et al., 1987; Healy, Malley and Stewart, 1990; Kudek, 1988), but studies have yet to appear on the more extreme cases of Parental Alienation Syndrome and Divorce Related Malicious Mother Syndrome.

The Divorce Related Malicious Mother Syndrome represents an important societal phenomenon. The disorder affects children, parents, attorneys, judges, guardians, mental health professionals, and others. Until this phenomenon is explored more thoroughly in the scientific and clinical 
literature, the problems imposed by individuals suffering from Divorce Related Malicious Mother Syndrome will continue to plague us. Hopefully, the present manuscript will stimulate research so that clinical and legal management guidelines can be developed.

\section{REFERENCES}

Artlitli, J. A. (1992). Factors related to custody, visitation, and child support for divorced fathers: An exploratory analysis. J. Div. Remarr. 17: 23-42.

Beal, E. W., and Hockman, D. (1991). Adult Children of Divorce, Delacorte Press, New York.

Cartwright, D. F. (1993), Expanding the parameters of parental alienation syndrome. Am. J. Fam. Ther. 21: 205-215.

Commission on Gender Bias in the Judicial System. (1992). Gender and justice in the courts: A report to the supreme court of Georgia. Georgia State Univ. Law Rev. 8: 539-807.

Ekman, P., and O'Sullivan, M. (1991). Who can catch a liar? American Psychologist, 46: 913-920.

Enos, D. M., and Handal, P. J. (1986). The relation of parental marital status and perceived family conflict to adjustment in white adolescents. J. Consult. Clin. Psychol. 54: 820-824.

Frost, A. K., and Pakiz, U. (1990). The effects of marital disruption on adolescence: Time as a dynamic. Am. J. Orthopsychiatry 60: 544-555.

Furstenberg, F. F., Morgan, S. P., and Allison, P. D. (1987). Paternal participation and children's well being after marital dissolution. Am. Sociological Rev. 52: 695-701.

Gardner, R. A. (1987). The Parental Alienation Syndrome and the Differentiation Between Fabricated and Genuine Child Sex Abuse, Creative Therapeutics, Cresskill, NJ.

Gardner, R. A. (1989). Family Evaluation in Child Custody Mediation, Arbitration, and Litigation, Creative Therapeutics, Cresskill, NJ.

Greif, G. L. (1985). Single Fathers, Lexington Books, Lexington, MA.

Grutman, R., and Thomas, B. (1990). Lawyers and Thieves, Simon \& Schuster, Englewood Cliffs, NJ.

Healy, J. M., Malley, J. E., and Stewart, A. J. (1900). Children and their fathers after parental separation. Am. J. Orthopsychiatry 60: 531-543.

Hetherington, E. N., and Arasteh, J. D. (eds.). (1988). Impacl of Divorce, Single Parenting and Step-Parenting on Children, Lawrence Erlbaum, Hillsdale, NJ. 
Heinz, H. R., and Heinz, S. A. (1993). Emotional incest: The tragedy of divorcing families. Am. J. Fam. Law 7: 169-174.

Hernandez, D. J. (1988). The demographics of divorce and remarriage. In Hetherington, E. M., and Arasteh, J. D. (eds.), Impact of Divorce, Single Parenting, and Step-Parenting on Children, Lawrence Erlbaum, Hillsdale, NJ, pp. 3-22.

Hodges, W. E (1991). Interventions for Children of Divorce, (second edition), Wiley, New York.

Keane, G. (1990). Florida Divorce Handbook, Pineapple Press, Sarasota, FL.

Koel, A., Clark, S. C., Phear, W. P., and Hauser, B. B. (1988). A comparison of joint and sole legal custody agreements. In Hetherington, E. M., and Arasteh, J. D. (eds.), Impact of Divorce, Single Parenting, and Step-Parenting on Children, Lawrence Erlbaum, Hillsdale, NJ, pp. 73-90.

Kressel, K. (1985). The Process of Divorce, Basic Books, New York.

Kurdek, L. (1988). Custodial mothers' perceptions of visitation and payment of child support by non-custodial fathers in families with low and high levels of pre-separation interparental conflict. J. Appl. Devel. Psychol. 9: 315-328.

Laosa, L. N. (1988). Ethnicity and single parenting in the United Stales. In Hetherington, E. M., and Arasteh, J. D. (eds.), Impact of Divorce, Single Parenting, and Step-Parenting on Children, Lawrence Erlbaum, Hillsdale, NJ, pp. 23-49.

Shepard, N. (1992). Child-visiting and domestic abuse. Child Welfare 71: 357-367.

Snyder, S. (1986). Pseudologia Fantastica in the borderline patient. Am. J. Psychiatry 143: 1287-1289.

Tillitski C. J. (1992). Fathers and child custody: Issues, trends, and implications for counseling. J. Ment. Health Counsel. 14: 351-361.

Turkat I. D. (1990). The Personality Disorders: A Psychological Approach to Clinical Management, Pergamon, New York.

Turkal, I. D. (1993). Questioning the mental health expert's custody report. Am. J. Fam. Law 7: 175-179. 